\title{
A rare case of a biloma mimicking a submucosal tumor arising from the lower esophagus
}

A 57-year-old woman presented with intermittent abdominal pain of 5 months' duration. Physical examination and laboratory tests were normal. Esophagogastroduodenoscopy showed a submucosal tumor (SMT) originating from the lower esophagus (> Fig.1). Endoscopic ultrasound (EUS) demonstrated a hypoechoic, homogeneous tumor $(27 \mathrm{~mm} \times$ $21 \mathrm{~mm}$ ) with a regular margin arising from the muscularis propria ( $\mathbf{F i g . 2}$ ). Submucosal tunneling endoscopic resection (STER) was performed. After the tumor was revealed, an injection needle was used to pierce the tumor to prevent additional injury to the aorta: a goldenyellow liquid flowed out. A $10-\mathrm{mL}$ sample of this liquid was taken for testing, and total bilirubin was found to be $146.3 \mu \mathrm{mol} / \mathrm{L}$. An esophageal biloma was suspected. To avoid infection due to rupture of the biloma, we stopped the procedure. After hemostasis with hot biopsy forceps in the tunnel, several clips were used to close the mucosal defect ( Video 1).

Subhepatic bile collections (bilomas) are usually caused by postoperative biliary injury in the liver or gallbladder fossa [1]; idiopathic bilomas are rare. In this paper, we report for the first time a rare case of a biloma mimicking a SMT arising from the lower esophagus in a patient with no history of surgery, abdominal trauma, liver disease, or biliary disease. Because it is hard, on the endoscopic view within the tunnel, to distinguish tumors from physiologic protrusions (especially the aorta) and from the normal muscular layer [2], during STER in our endoscopy center an injection needle was used to pierce the tumor in order to prevent additional injury to the aorta. Hence, a biloma was identified and potential rupture of the tumor during STER was avoided.

Although EUS is widely recognized for evaluating a SMT $[3,4]$, we still consider

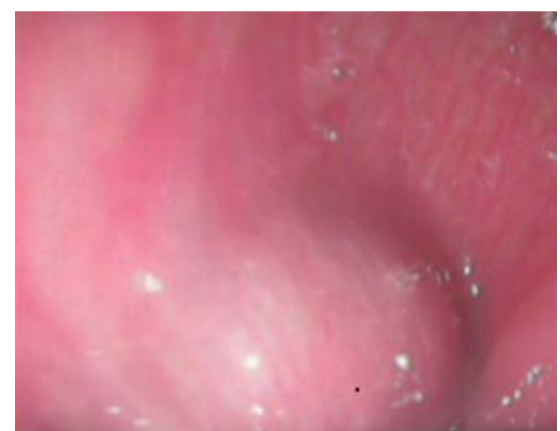

- Fig. 1 Esophagogastroduodenoscopy showed a submucosal tumor originating from the lower esophagus.

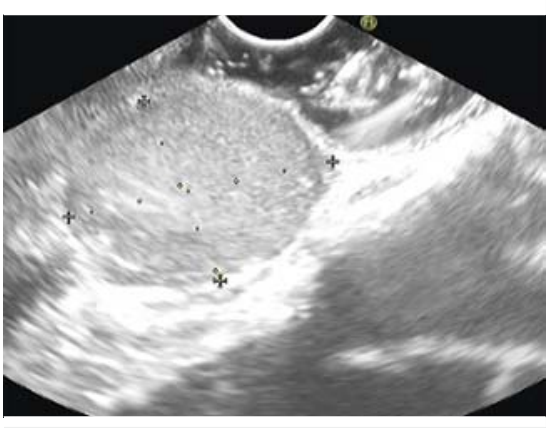

Fig. 2 Endoscopic ultrasound demonstrated a hypoechoic, homogeneous tu$\operatorname{mor}(27 \mathrm{~mm} \times 21 \mathrm{~mm})$ with a regular margin arising from the muscularis propria.

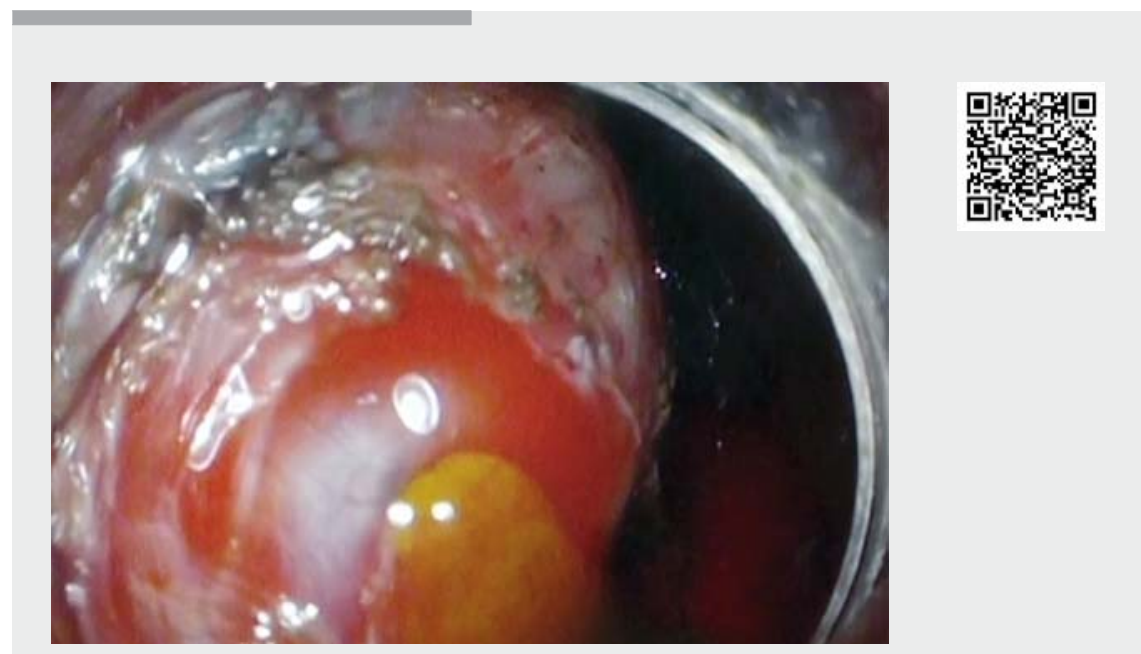

Video 1 Submucosal tunneling endoscopic resection was performed and an esophageal biloma was suspected.

that use of an injection needle is necessary to confirm the identity of a SMT during STER.

Endoscopy_UCTN_Code_CPL_1AH_2AZ

\section{Competing interests}

The authors declare that they have no conflict of interest.
The authors

Wen Liu, Sheng Wang, Jintao Guo, Xiang Liu, Nan Ge, Guoxin Wang, Siyu Sun

Department of Gastroenterology, Shengjing Hospital of China Medical University, Shenyang, P. R. China 
Corresponding author

\section{Siyu Sun, MD}

Department of Gastroenterology, Shengjing Hospital of China Medical University, No. 36, Sanhao Street, Shenyang, Liaoning Province, P. R. China, 110004

Fax: +86-24-23892617

sunsy@sj-hospital.org

\section{References}

[1] Choudhary N, Duseja A, Kalra N et al. Hepatobiliary and pancreatic: intrahepatic biloma after blunt abdominal trauma. J Gastroenterol Hepatol 2011; 26: 1342

[2] Ge N, Sun SY, Wang S et al. Endoscopic ultrasound-assisted tunnel-type endoscopic submucosal dissection for the treatment of esophageal tumors arising in the muscularis propria (with video). Endosc Ultrasound 2013; 2: 11-15

[3] Sahai AV. EUS is trending. Endosc Ultrasound 2018; 7: 353-355

[4] Pesenti C, Bories E, Caillol F et al. Characterization of subepithelial lesions of the stomach and esophagus by contrast-enhanced EUS: a retrospective study. Endosc Ultrasound 2019; 8: 43-49

Bibliography

Endoscopy 2021; 53: E283-E284

DOI 10.1055/a-1244-9393

ISSN 0013-726X

published online 8.10 .2020

(C) 2020. Thieme. All rights reserved.

Georg Thieme Verlag KG, Rüdigerstraße 14,

70469 Stuttgart, Germany
ENDOSCOPY E-VIDEOS

https://eref.thieme.de/e-videos

口㺼回 Endoscopy E-Videos is a free access online section, reporting 田: on interesting cases and new techniques in gastroenterological endoscopy. All papers include a high quality video and all contributions are freely accessible online.

This section has its own submission website at

https://mc.manuscriptcentral.com/e-videos 